\title{
Erratum to: Sex Disparity in Gastric Cancer: Female Sex is a Poor Prognostic Factor for Advanced Gastric Cancer
}

Hae Won Kim, MD ${ }^{1,4}$, Jie-Hyun Kim, MD, PhD ${ }^{1,4,5}$, Beom Jin Lim, MD, PhD ${ }^{2,4}$, HyunKi Kim, MD, PhD ${ }^{2}$, Hoguen Kim ${ }^{2}$, Jae Jun Park, MD, PhD ${ }^{1,4}$, Young Hoon Youn, MD, PhD ${ }^{1,4}$, Hyojin Park, MD, PhD ${ }^{1,4}$, Sung Hoon Noh, MD, $\mathrm{PhD}^{3}$, Jong Won Kim, MD, $\mathrm{PhD}^{3,4}$, and Seung Ho Choi, MD, $\mathrm{PhD}^{3,4}$

${ }^{1}$ Department of Internal Medicine, Institute of Gastroenterology, Yonsei University College of Medicine, Seoul, Korea; ${ }^{2}$ Department of Pathology, Gangnam Severance Hospital, Yonsei University College of Medicine, Seoul, Korea;

${ }^{3}$ Department of Surgery, Institute of Gastroenterology, Yonsei University College of Medicine, Seoul, Korea; ${ }^{4}$ Gangnam Severance Hospital, Yonsei University College of Medicine, Seoul, Korea; ${ }^{5}$ Department of Internal Medicine, Gangnam Severance Hospital, Yonsei University College of Medicine, Seoul, Korea

\section{ERRATUM TO: ANN SURG ONCOL}

DOI 10.1245/S10434-016-5448-0

In the original article there was an error in Fig. $1 b$.

Following is the corrected figure.

FIG. 1 Kaplan-Meier curve for the OS rate in patients with advanced gastric cancer. a Survival rates of young patients ( $\leq 45$ years); females had worse OS than males. b Survival rates of old patients ( $>45$ years); no significant differences in OS were observed between the two sex groups. OS overall survival (a) Young patients ( $\leq 45$ years)

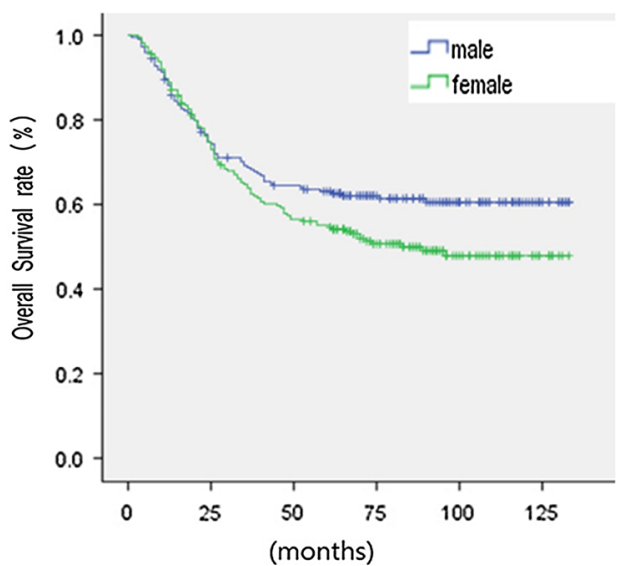

(b) Old patients ( $>45$ years)

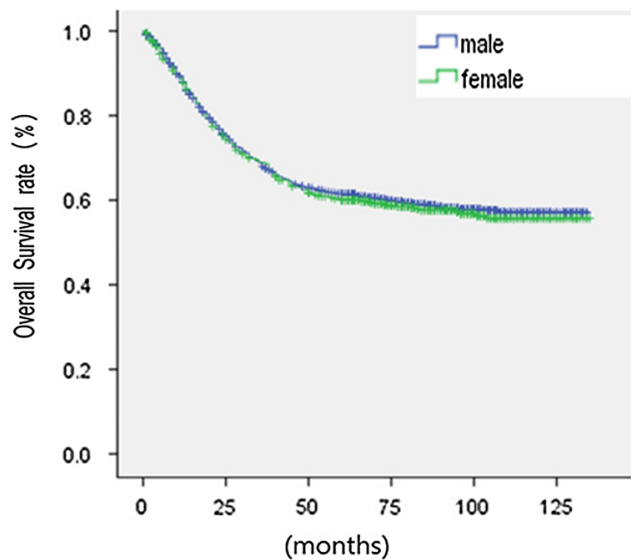

The online version of the original article can be found under doi:10. 1245/s10434-016-5448-0.

(C) Society of Surgical Oncology 2016

Published Online: 5 August 2016

J.-H. Kim, MD, PhD

e-mail: otilia94@yuhs.ac

B.-J. Lim, MD, PhD

e-mail: bjlim@yuhs.ac 